\title{
Role of fucosyltransferases in the association between apomucin and Lewis antigen expression in normal and malignant gastric epithelium
}

\author{
A López-Ferrer, C de Bolós, C Barranco, M Garrido, J Isern, I Carlstedt, C A Reis,
} J Torrado, F X Real

\begin{abstract}
Background-In normal gastric epithelium, MUC5AC is detected in superficial epithelium associated with Lewis type 1 antigens and MUC6 is detected in antral glands with Lewis type 2 . Therefore, the stomach constitutes an excellent model to examine the role of glycosyltransferases in determining the specificity of apomucin glycosylation.

Aims-To determine the molecular basis of this association and to examine changes in expression of gastric and intestinal apomucins and their association with Lewis antigens during the gastric carcino-
\end{abstract} genesis process.

Methods-Fucosyltransferase (FUT1, FUT2, FUT3) and mucin (MUC5AC, MUC6) transcripts were detected using reverse transcription-polymerase chain reaction. Apomucin (MUC2, MUC4, MUC5AC, MUC6) and Lewis antigen (types 1 and 2) expression were analysed using single and double immunohistochemistry and in situ hybridisation.

Results-In the normal stomach, FUT1 is exclusively detected associated with MUC6; FUT2 is only detected when MUC5AC is present. This co-regulation is lost in gastric tumours, as is differential expression of MUC5AC and MUC6 in normal gastric epithelial cells. In gastric tumours, especially those with the intestinal phenotype, MUC2 and MUC4 genes are upregulated, and gastric-type and intestinal-type mucins are coexpressed. These changes are early events in the gastric carcinogenesis process, as they are detected in intestinal metaplasia.

Conclusions-The glycosylation pattern found in normal gastric epithelium is dictated by the specific set of fucosyltranferases expressed by the cells rather than by the apomucin sequence. The development of intestinal metaplasia and gastric cancer is associated with the appearance of cellular phenotypes that are absent from normal epithelium.

(Gut 2000;47:349-356)

Keywords: fucosyltransferases; gastric carcinogenesis; gastric mucins; Lewis antigens

Mucins are highly glycosylated proteins and the principal components of mucus, a viscoelastic gel that covers the surface of epithelial tissues. Their molecular heterogeneity resides in both the apomucin and carbohydrate chains which are linked by an $O$-glycosidic bond. Until now, cDNAs from nine different mucin genes have been cloned (MUC1-MUC4, MUC5B, MUC5AC, MUC6-MUC8). ${ }^{1-11}$ Each apomucin gene has a characteristic pattern of tissue distribution and none of the apomucins is restricted to a single epithelium. ${ }^{12}{ }^{13}$ To date, there are only indirect data concerning the relationship between the mucin gene expression pattern and specific function of mucus in a given tissue.

Mucus covering the gastric epithelium plays a major role in protection from acid $\mathrm{pH}$ and mechanical aggression. The antral epithelium displays two well characterised populations of mucous secreting cells: the superficial epithelium and the deep glands. Cells in the superficial epithelium express MUC5AC in association with type 1 Lewis antigens $\left(\mathrm{Le}^{\mathrm{a}}\right.$ and $\left.\mathrm{Le}^{\mathrm{b}}\right)$ and produce neutral mucins. In contrast, deep gland cells express MUC6 in association with type 2 Lewis antigens $\left(\mathrm{Le}^{\mathrm{x}}\right.$ and $\mathrm{Le}^{\mathrm{y}}$ ) and secrete acid mucins. ${ }^{14}$ Therefore, the gastric epithelium constitutes an adequate model system to study the relationship between apomucin expression and glycosylation. It is currently not known if this specific pattern of glycosylation is determined by the primary amino acid sequence of the apomucins or by the fucosyltranferases expressed in each cell type. Seven human fucosyltranferase genes have been cloned. Among them, FUT1, FUT2, and FUT3 code for the enzymes responsible for Lewis antigen synthesis in epithelial cells. ${ }^{15} 16$ FUT1 and FUT2 are the $\alpha-1,2-$ fucosyltransferases responsible for the synthesis of Lewis type 2 (Gal $\beta 1,4-G l c N A c)$ and type 1 (Gal $\beta 1,3-G l c N A c)$ antigen precursors. ${ }^{15} 17$ The $\alpha-1,3 / 4$ fucosyltransferase, FUT3, is involved in the synthesis of all Lewis antigens by adding an $\alpha$-fucose to the type 1 and type 2 precursor structures. ${ }^{16}$

Alterations in expression of Lewis structures have been described in several gastric pathologies. Among them are ectopic expression of $\mathrm{Le}^{\mathrm{a}}$ in intestinal metaplasia from individuals with the secretor phenotype, ${ }^{18} 19$ which has been proposed as a marker of increased cancer

Abbreviations used in this paper: RT-PCR, reverse transcription-polymerase chain reaction; MoAb, monoclonal antibody; AP, alkaline phosphatase; PBS, phosphate buffered saline; HRP, horseradish peroxidase; DTT, dithiotreitol; PFA, paraformaldehyde; DIG, digoxigenin. 
Table 1 Characteristics of antibodies used in this study

\begin{tabular}{llll}
\hline Antibody & Specificity & Type & Reference \\
\hline T-174 & Lewis a & MoAb & 23 \\
T-218 & Lewis b & MoAb & 23 \\
$77 / 180$ & Lewis y & MoAb & 15 \\
LDQ10 & MUC2 TR & MoAb & 24 \\
Anti-MUC4 & MUC4 TR & Rabbit polyclonal & $\star$ \\
CLH2 & MUC5AC TR & MoAb & 22 \\
LUM5-1 & MUC5AC, non TR & Rabbit polyclonal & 25 \\
Anti-MUC6 & MUC6 TR & Rabbit polyclonal & 14 \\
\hline
\end{tabular}

*De Bolós, unpublished.

$\mathrm{MoAb}$, monoclonal antibody.

risk, and upregulation of sialyl- $\mathrm{Le}^{\mathrm{x}}$ related to an increased risk of metastasis and poor prognosis in gastric cancer patients..$^{20}$ In addition, upregulation of mucin genes that are normally absent from a healthy stomach (that is, MUC2 and MUC3), ${ }^{21}$ as well as downregulation of gastric mucin genes associated with tumour type and stage (that is, MUC5AC) have been described. ${ }^{22}$

Based on these findings, we attempted to elucidate the molecular basis of the association between apomucins and Lewis antigens in the normal stomach, and changes in apomucin and Lewis antigens in gastric neoplastic and preneoplastic lesions. Firstly, we analysed mucin and FUT transcripts in the normal stomach. We also examined expression of gastric (MUC5AC and MUC6) and intestinal (MUC2 and MUC4) mucin genes in gastric tumours, and their association with Lewis antigens and expression of FUT1-FUT3 mRNA. In addition, we analysed mucin gene expression and coexpression of apomucins and Lewis antigens in lesions representative of the sequential carcinogenesis process.

\section{Methods}

TISSUE SAMPLES

Normal and neoplastic stomach tissue samples were obtained at surgery performed at Hospital Ntra Sra Aránzazu (San Sebastian, Spain) and Hospital del Mar (Barcelona), snap frozen in isopentane cooled to $-80^{\circ} \mathrm{C}$, and embedded in OCT (optimal cutting temperature) for cryostat sections. Normal stomach samples were obtained from individuals who underwent gastrectomy for duodenal ulcer or from macroscopically normal areas at a distance $>10 \mathrm{~cm}$ from a gastric cancer. Biopsies from gastric endoscopies were fixed in $10 \%$ formaldehyde and embedded in paraffin. A diagnosis was made on the basis of haematoxylin/eosin staining. Intestinal metaplasia was defined as follows: complete type when absorptive, Paneth, and goblet cells were identified; and incomplete type when columnar and goblet cells were present. For RNA extraction, normal and tumour samples were collected from patients undergoing surgery, snap frozen as soon as possible, and stored at $-80^{\circ} \mathrm{C}$. In some specimens, superficial and deep epithelium were separated by scraping.

ANTIBODIES AND IMMUNOHISTOCHEMICAL ASSAYS Characteristics of the antibodies used in this study are shown in table 1. Monoclonal antibodies (MoAb) T-174, ${ }^{23} \mathrm{~T}-218,{ }^{23} \mathrm{~B} 12$ (Dr
R Castro, Barcelona, Spain), and CLH2 $2^{22}$ were used as undiluted hybridoma supernatant; MoAbs $77 / 180^{14}$ and LDQ $10^{24}$ were purified and used at $25 \mu \mathrm{g} / \mathrm{ml}$. Rabbit polyclonal serum LUM5-1, raised against a synthetic peptide from the $\mathrm{COOH}$ terminal domain of MUC5AC, was used at $1 / 1000-1 / 2000 .^{25}$ MUC5AC was always detected with LUM5-1 except for the MUC5AC/MUC6 double labelling experiments which were performed with CLH2 MoAb. Rabbit polyclonal anti-MUC4 antibodies were raised against a KLH conjugate of a synthetic peptide corresponding to the tandem repeat sequence of MUC4 (TSSASTGHATPLPVTD) following procedures reported elsewhere. ${ }^{14}$ Polyclonal anti-MUC4 and anti-MUC6 antibodies were purified by affinity chromatography on synthetic peptides as previously described ${ }^{14}$ and were used at $1 / 10$ $1 / 50$ dilutions. The specificity of all antibodies has been reported previously (see table 1), except for that of MUC4. Specificity of the anti-MUC4 affinity purified antibodies was determined by ELISA and by peptide inhibition assays using immunohistochemistry, as previously described. ${ }^{14}$ No reactivity was detected for any of the peptides encompassing the tandem repeat sequences of MUC1-MUC8, except for that of MUC4 (De Bolòs, unpublished data). Pre-immune rabbit serum was used as a negative control.

The indirect immunoperoxidase technique was performed as described previously. ${ }^{12}$ For double labelling immunoassays, paraffin sections were rehydrated and fixed with cold acetone for 10 minutes. Endogenous peroxidase and alkaline phosphatase (AP) were blocked with $4 \% \quad \mathrm{H}_{2} \mathrm{O}_{2}$ and $3 \mathrm{mM}$ levamisole in phosphate buffered saline (PBS) for 10 and 15 minutes, respectively. Non-specific binding sites were blocked by incubating the sections with $5 \%$ skim milk in PBS/0.04\% Tween 20. The two primary antibodies from different species were diluted in PBS with $1 \%$ bovine serum albumin, and incubated together for 1.5 hours. After four washes with PBS, sections were incubated with a mix of the two secondary antibodies, one labelled with horseradish peroxidase (HRP) and the other with AP (Dako, Denmark) for one hour. Sections were washed with PBS and then with $0.2 \mathrm{M}$ Tris, $\mathrm{pH}$ 8.2. AP was developed with $0.1 \%$ Fast BlueBB, $0.02 \%$ Naphtol AS-MX phosphate in $0.2 \mathrm{M}$ Tris, $\mathrm{pH}$ 9.1, and HRP was developed with $0.5 \%$ diaminobenzidine in PBS with $0.1 \% \mathrm{H}_{2} \mathrm{O}_{2}$. After washing in distilled water, sections were mounted with an aqueous mounting medium (Aquatex, Merck, Germany). Scoring of reactions was performed as described previously. ${ }^{12}$ Percentage of reactive cells was an estimate of the whole tissue section. Double labelling immunofluorescence assays were performed as described previously. ${ }^{14}$ Confocal microscopy analysis was performed using a Leica TCS NT instrument.

For immunoelectron microscopy, indirect double labelling techniques with $\mathrm{CLH} 2$ and anti-MUC6.1 antibodies were performed on tissues embedded in Lowicryl $4 \mathrm{KM}$, as described elsewhere. ${ }^{26}$ The anti-MUC6.1 antibodies were visualised with Protein A-gold 
complexes (5 nm Ø) (Department of Cell Biology, School of Medicine, Utrecht University, the Netherlands); CLH2 antibody was detected with goat antimouse Ig (Dako) and Protein A-gold complexes (15 nm Ø) (Utrecht University). Reactivity was visualised using a Philips CM100 electron microscope.

WESTERN BLOTTING

Briefly, tumour samples were homogenised in

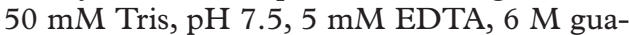
nidium hydrochloride, $1 \mathrm{mM}$ phenylmethyl sulphonyl fluoride, reduced with $100 \mathrm{mM}$ dithiotreitol (DTT) (Sigma, Missouri, USA), and incubated in the dark for 24 hours. Sulphhydryl groups were stabilised by adding $250 \mathrm{mM}$ iodoacetamide (Sigma) and stirring in the dark for an additional 24 hours. ${ }^{27}$ Proteins $(50 \mu \mathrm{g} /$ well) were separated using a $6 \%$ sodium dodecyl sulphate-polyacrylamide gel, and western blotting was performed as described previously $^{14}$ except that membranes were deglycosylated with $10 \mathrm{mM}$ sodium periodate

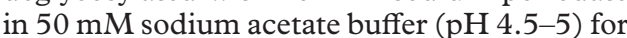
one hour in the dark.

IN SITU HYBRIDISATION

Synthetic oligonucleotides (48mers) corresponding to the tandem repeat sequences of mucin genes were used. Sense oligonucleotides encompassing the same sequences were used as negative controls in selected experiments. Oligonucleotides were labelled with digoxigenin (DIG) following the manufacturer's instructions (Boehringer Mannheim, Mannheim, Germany). Samples were immediately fixed in $4 \%$ paraformaldehyde (PFA), embedded in paraffin, and stored at $4^{\circ} \mathrm{C}$. Sections were deparaffinised and rehydrated. Proteinase $\mathrm{K}$ digestion $(1 \mu \mathrm{g} / \mathrm{ml}$ in $0.1 \mathrm{M}$ Tris $\mathrm{HCl}, \mathrm{pH} 7$, $0.5 \mathrm{M}$ EDTA) was performed for 15 minutes at $37^{\circ} \mathrm{C}$. Samples were fixed with $4 \%$ PFA for 15 minutes and treated with $0.1 \mathrm{M}$ triethanolamine, $\mathrm{pH} 8$, and $0.25 \%$ acetic anhydride for 10 minutes. After prehybridisation in $4 \times \mathrm{SSPE}$ with $1 \%$ Denhardt's at $42^{\circ} \mathrm{C}$ for one hour, sections were dehydrated and hybridised overnight at $40^{\circ} \mathrm{C}$ with DIG labelled oligonucleotides $(200-400 \mu \mathrm{g} / \mathrm{ml})$ diluted in $4 \times \mathrm{SSPE}, 1 \%$ Denhardt's, $50 \%$ formamide, $20 \mathrm{mM}$ DTT, $0.1 \mathrm{M}$ sodium phosphate, $\mathrm{pH} 7.2,1 \%$ sarkosyl, and tRNA $(250 \mu \mathrm{g} / \mathrm{ml})$. Post-hybridisation washes were done stepwise from $4 \times \mathrm{SSPE}$ at $20^{\circ} \mathrm{C}$ to a final wash with $0.1 \times \operatorname{SSPE}$ at $42^{\circ} \mathrm{C}$. Sections were rehydrated, dried, and incubated with 5\% normal horse serum. AP conjugated sheep anti-DIG antibodies (Boehringer Mannheim) were incubated overnight at $4^{\circ} \mathrm{C}$. AP was developed overnight at $4^{\circ} \mathrm{C}$ using nitroblue tetrazolium/5-bromo-4-chloro-3-indolylphosphate (Promega, Wisconsin, USA) in 100 $\mathrm{mM} \mathrm{NaCl}, 50 \mathrm{mM} \mathrm{MgCl}, 100 \mathrm{mM}$ Tris $\mathrm{HCl}$, $\mathrm{pH}$ 9.5. Slides were rinsed and mounted in Aquatex.

The antisense oligonucleotide sequences used were: MUC2 (5' GGT CTG TGT GCC GGT GGG TGT TGG GGT TGG GGT CAC CGT GGT GGT GGT 3'), MUC4 (5' GTC GGT GAC AGG AAG AGG GGT GGC GTG ACC TGT GGA TGC TGA
GGA AGT 3'), MUC5AC (5' AGG GGC AGA AGT TGT GCT CGT TGT GGG AGC AGA GGT TGT GCT GGT TGT 3'), and MUC6 (5' CAT CTG TGC GTG GGT AGG GGT GAT GAC TGT GTG AGT ACT TGG AGT CAC 3').

REVERSE TRANSCRIPTION-POLYMERASE CHAIN REACTION (RT-PCR)

Total RNA was isolated using the guanidinium thiocyanate/phenol/chloroform extraction method. ${ }^{28}$ cDNA was synthesised using $5 \mu \mathrm{g}$ of DNase I treated RNA with $200 \mathrm{U}$ of M-MLV reverse transcriptase. FUT1 and FUT2 transcripts were amplified by PCR using primers described by Kelly and colleagues. ${ }^{15} 17 \mathrm{cDNA}$ was amplified under the following conditions: 1.5 minutes at $94^{\circ} \mathrm{C}$, annealing/extension at $72^{\circ} \mathrm{C}$ for 2.5 minutes (40 cycles), and final elongation at $72^{\circ} \mathrm{C}$ for 10 minutes. For FUT3 mRNA detection, primers published by Cameron and colleagues ${ }^{16}$ were used. PCR conditions were: 1.5 minutes at $94^{\circ} \mathrm{C}, 1.5 \mathrm{~min}$ utes at $70^{\circ} \mathrm{C}$, two minutes at $72^{\circ} \mathrm{C}$ ( 40 cycles), and final extension at $72^{\circ} \mathrm{C}$ for 10 minutes. $\mathrm{K}$-ras and $\beta$-actin primers were used to control for mRNA quality. ${ }^{29} 30$ The size of the PCR products was $510 \mathrm{bp}$ for FUT1, $198 \mathrm{bp}$ for FUT2, 582 bp for FUT3, 265 bp for K-ras, and $349 \mathrm{bp}$ for $\beta$-actin.

Mucin transcripts were amplified using the following primers: MUC5AC sense GTA CCA GAA CAG TCG ACC T, MUC5AC antisense CTC TTC CAC CTC GGT GTA GC, MUC6 sense GTC CAC TTC TGC TTC GAT CCA CTC, and MUC6 antisense GGA CCT GTG GAA GAG ACA TGA CTG; oligonucleotides were selected based on published sequences. ${ }^{931}$

The conditions for amplification were, for MUC5AC, one minute at $94^{\circ} \mathrm{C}, 0.5$ minutes at $58^{\circ} \mathrm{C}$, and 0.5 minutes at $72^{\circ} \mathrm{C}(35$ cycles $)$ and for MUC6, one minute at $94^{\circ} \mathrm{C}, 0.5$ minutes at $70^{\circ} \mathrm{C}$, and 0.5 minutes at $72^{\circ} \mathrm{C}$ (30 cycles). The size of the PCR products was $257 \mathrm{bp}$ for MUC5AC and 359 bp for MUC6. PCR products were separated by $2 \%$ agarose gel electrophoresis and stained with ethidium bromide.

\section{Results}

MUCIN AND FUCOSYLTRANSFERASE GENE EXPRESSION IN NORMAL GASTRIC MUCOSA

In normal stomach, gastric mucin genes were expressed in two different cell populations: MUC5AC was detected in superficial epithelium and MUC6 in deep glands. In these cell populations, MUC5AC and MUC6 are associated with Lewis type 1 and type 2 antigens, respectively. ${ }^{14}$ For intestinal mucin genes, MUC2 was detected in a variable proportion of cells in $50 \%$ of fundic and antral samples, as described previously. ${ }^{12}$ MUC4 specific affinity purified polyclonal antibodies were used to determine MUC4 expression in normal stomach: this apomucin was detected in the superficial epithelium of 2/10 fundic and 3/14 antral samples. Similar results were obtained by in situ hybridisation: MUC4 was found in 1/2 and $2 / 4$ fundic and antral tissue samples, respectively (data not shown). In some cases, slight 


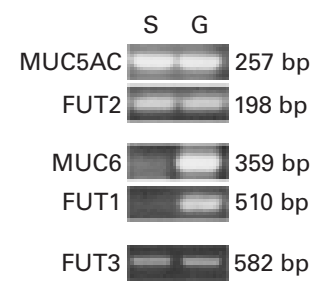

Figure 1 Mucin and fucosyltransferase $m R N A$ expression in gastric mucosa scrapings detected by RT-PCR (S, superficial epithelium; $G$, deep glands). MUC6 and FUT1 were detected only in the deep gland scrapings. MUC5AC and FUT2 were detected in both superficial epithelium and deep glands, suggesting that cells from the superficial epithelium contaminated the deep gland fraction. gastritis was observed. Therefore, MUC4 (in common with MUC2) is expressed mainly in the intestine but not in the stomach.

Association between expression of MUC5AC and MUC6, and FUT1, FUT2, and FUT3 genes was analysed by RT-PCR using RNA from superficial epithelium and deep gland scrapings of normal stomach. Results are shown in fig 1. In normal stomach, transcripts of FUT1, the $\alpha 1,2-$ fucosyltransferase that catalyses the transfer of fucose to type 2 precursor structures, were detected exclusively in samples from deep glands in association with MUC6 transcripts $(n=8)$. In contrast, transcripts of FUT2, the transferase involved in the synthesis of Lewis type 1 antigens, were found in normal samples from both superficial epithelium and glands, as was the case for MUC5AC transcripts, suggesting that scrapings did not contain a pure population of deep epithelial cells (fig 1). Transcripts of FUT3, the $\alpha-1,3 / 4$ fucosyltransferase involved in the synthesis of all Lewis antigens, were detected in all samples from normal tissues.

EXPRESSION OF GASTRIC AND INTESTINAL APOMUCINS IN GASTRIC CANCER: COEXPRESSION WITH LEWIS ANTIGENS

Antibodies detecting gastric and intestinal apomucins were first used to analyse their expression in a panel of 35 fresh frozen stomach tumours obtained at surgery. MUC5AC was detected, using the LUM5-1 polyclonal antiserum, in 3/19 intestinal-type and in 3/15 diffuse-type tumours. In contrast, MUC6 was detected in the majority of intestinal (18/18) and diffuse (15/16) tumours. MUC2 and MUC4 were more commonly detected in intestinal (9/15 and 13/16, respectively) than in diffuse-type tumours (5/17 and $6 / 15$, respectively). A cytoplasmic diffuse staining was observed for all antiapomucin antibodies. Differences in staining rate between intestinal and diffuse tumours were statistically significant for both MUC2 and MUC4 $(p=0.039$ and 0.016 , respectively). The highest percentage of positive cells was detected with the anti-MUC6 antibodies: $>50 \%$ in intestinaltype tumours and $30-100 \%$ in the diffuse type. MUC5AC apomucin was always expressed in $<50 \%$ of cells. For MUC2 and MUC4, a high degree of heterogeneity regarding the number of positive cells was found in both types of gastric tumours $(10-100 \%)$. These results were confirmed by in situ hybridisation: MUC5AC was detected in 4/7 tumours, the proportion of positive cells ranging from 10 to $60 \%$, whereas MUC6 was expressed in 7/7 samples. Representative results of MUC4 expression using immunohistochemical and in situ hybridisation assays are shown in fig $2 \mathrm{~A}$ and $2 \mathrm{~B}$. To confirm that several apomucin genes are expressed in the same tumour, reduced and carboxymethylated tumour homogenates were analysed by western blotting on sodium periodate treated membranes. Figure 2C shows detection of MUC2, MUC4, MUC5AC (detected with the $\mathrm{CLH} 2 \mathrm{MoAb}$ ), and MUC6 in tumour samples.

To determine if the differential distribution of MUC5AC and MUC6, and their association with Lewis antigens, was maintained in gastric
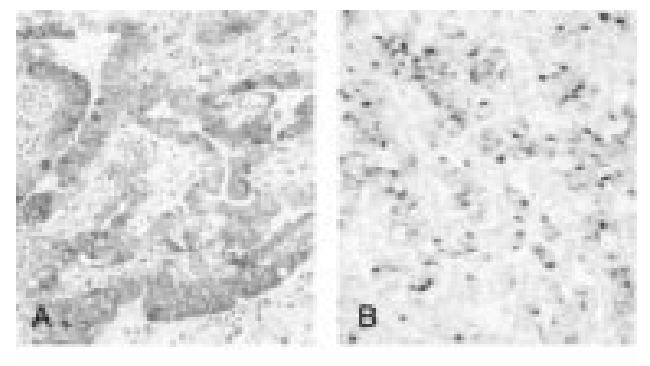

C

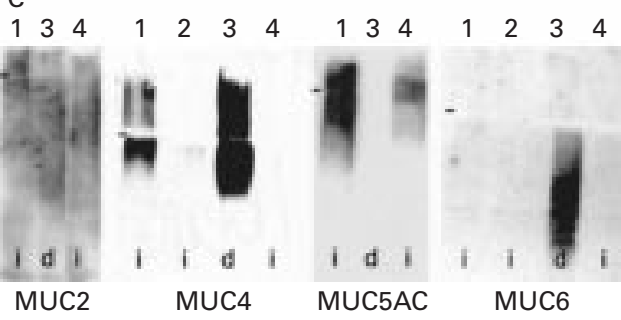

Figure 2 Mucin expression in gastric tumours. (A) MUC4 detected by immunohistochemistry in an intestinal-type tumour. (B) MUC4 expression by in situ hybridisation in a diffuse-type tumour (original magnification: $A \times 200 ; B \times 100)$. (C) Coexpression of several apomucin genes in gastric tumours: western blot detection of MUC2, MUC4, MUC5AC, and MUC6 apomucins in lysates of intestinal (i) $(1,2,4)$ and diffuse (d) (3) gastric tumours. Nitrocellulose membranes were treated with $100 \mathrm{mM}$ sodium periodate before immunodetection. Several apomucins are detected in the same tumour sample. Markers (-) indicate the borders between running and stacking gels.

tumours, double labelling immunohistochemical techniques were used. Three patterns of gastric apomucin expression were found: MUC5AC+/MUC6+, MUC5AC-/MUC6+, and MUC5AC+/MUC6-. Cells coexpressing MUC5AC and MUC6, a phenotype absent from the normal gastric epithelium, were identified in 9/10 intestinal (fig 3A) and 3/7 diffuse gastric carcinomas. Figure 3B shows colocalisation of the two apomucins in mucus droplets of an intestinal-type tumour cell using double labelling immunoelectron microscopy. Regardless of the apomucins expressed in the tumour, both types of Lewis antigens were detected, indicating that the association between apomucin and Lewis antigens is lost on neoplastic transformation. MUC5AC/Lewis type $2+$ cells were detected in 3/9 intestinal and 3/6 diffuse tumours, whereas MUC6/Lewis type 1+ cells were found in $7 / 9$ intestinal and $4 / 6$ diffuse carcinomas (fig 3C, D). Similarly, coexpression of MUC2 and MUC4 apomucins with Lewis type 1 and type 2 antigens was observed (data not shown). These patterns of apomucin/Lewis antigens were not detected in normal gastric epithelium and represent the appearance of an aberrant cell phenotype.

RELATION BETWEEN EXPRESSION OF

MUC5AC/MUC6 AND FUCOSYLTRANSFERASE GENES IN GASTRIC TUMOURS

The lack of association between apomucin and Lewis antigens in gastric tumours suggests alterations in the pattern of FUT gene expression. We analysed the pattern of mucin and fucosyltransferase transcripts in tumour samples. In most cases (10/14), MUC5AC, MUC6, FUT1, and FUT2 were simultaneously 


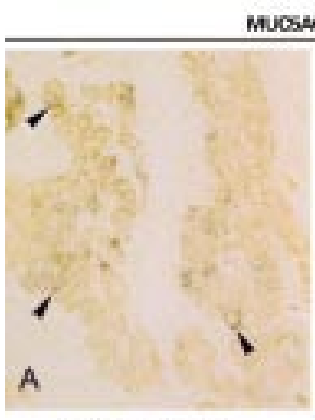

Mucsac/ trpez

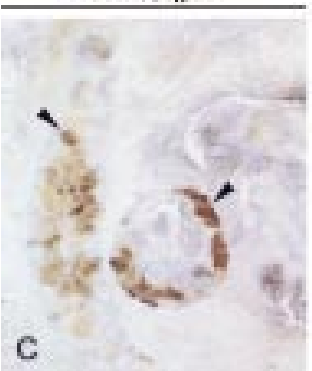

Figure 3 Gastric cancers contain cells displaying abnormal patterns of apomucin/Lewis antigen coexpression. (A) Double labelling immunohistochemical detection of MUC5AC (blue) and MUC6 expression (light brown) cells. Doubly labelled cells display a dark brown colour (original magnification $\times 400$ ). (B) Double labelling immunoelectron microscopy using antibodies against MUC5AC (CLH2) and MUC6 (anti-MUC6.1) and sections from Lowicryl 4 KM embedded tissues. Mouse antibodies were detected using $15 \mathrm{~nm}$ gold particles (arrowheads) and rabbit antibodies using $5 \mathrm{~nm}$ gold particles (arrows) (original magnification $\times 63$ 000). (C) Double labelling immunohistochemical detection of MUC5AC (brown) and Lewis y (blue). (D) Double labelling immunohistochemical detection of MUC6 (brown) and Lewis b (blue). Arrowheads in $(A),(C)$, and (D) indicate coexpression in tumour cells (original magnification $\times 400$ ).

Table 2. Mucin and fucosyltransferase $m R N A$ expression in gastric tumours detected using RT-PCR

\begin{tabular}{lllll}
\hline & MUC5AC & MUC6 & FUT1 & FUT2 \\
\hline $\mathrm{n}=10$ & + & + & + & + \\
$\mathrm{n}=2$ & + & - & + & + \\
$\mathrm{n}=1$ & - & + & + & + \\
$\mathrm{n}=1$ & + & - & - & + \\
\hline
\end{tabular}

detected; in two cases, MUC5AC was detected in association with FUT1 and FUT2 in the absence of MUC6 transcripts. In one of these cases, immunohistochemical analysis confirmed expression of MUC5AC, Lewis type 1, and Lewis type 2. This finding supports the conclusion that MUC5AC apomucin glycosylation is dictated by fucosyltransferases. In two additional cases, mucin and FUT transcripts showed other expression patterns (table 2, fig 4). FUT3 transcripts were detected in $12 / 14$ of the tumour samples tested.

DETECTION OF APOMUCINS AND LEWIS ANTIGENS IN PRENEOPLASTIC LESIONS

Because gastric cancers display abnormal patterns of apomucin and Lewis antigen expression, we analysed at which stage in the stomach carcinogenesis process these changes occur using paraffin embedded samples obtained at gastroscopy (table 3 ). In chronic gastritis $(n=10)$, the pattern of gastric and intesti-
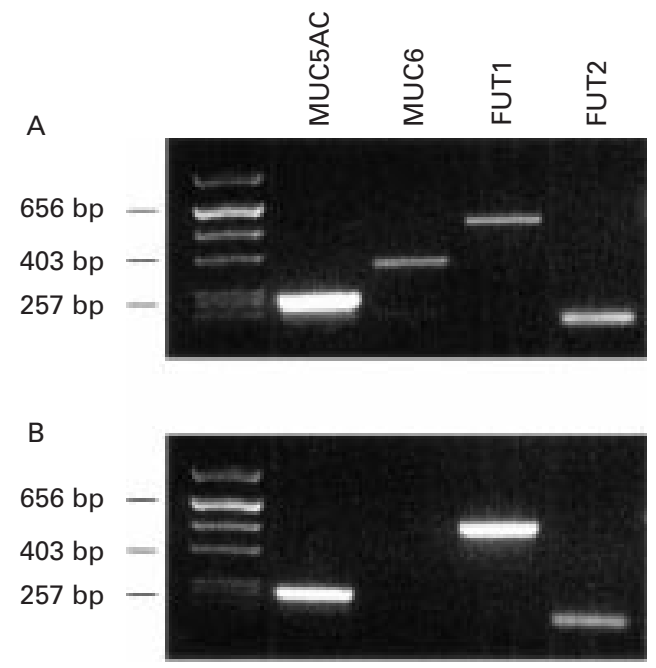

Figure 4 RT-PCR analysis of fucosyltransferase (FUT1 and FUT2) and mucin (MUC5AC and MUC6)

transcripts in two gastric tumours ( $A$ and $B)$. There was no association between the presence of MUC5AC and MUC6, and FUT2 and FUT1 transcripts, respectively.

nal apomucin expression was similar to that of normal tissues. In one case, MUC6 was detected in both the deep glands and the superficial epithelium. MUC4 was detected in $6 / 8$ cases in the superficial epithelium whereas MUC2 was generally undetectable (1/10). Antral glands were always unreactive with the antibodies against the intestinal mucins. Helicobacter pylori was detected in 3/9 samples with gastritis with no correlation with expression of MUC2 and MUC4.

In incomplete and complete intestinal metaplasia, expression of MUC5AC and MUC6 was downregulated in some cases. In contrast, MUC2 and MUC4 expression was activated in most cases of intestinal metaplasia, whether incomplete $(n=10)$ or complete $(n=4)$. The proportion of MUC2 expressing cells was generally higher $(80-100 \%)$ than that of MUC4 (20-70\%). Perinuclear staining was observed with the antibodies detecting mucin tandem repeat sequences whereas vacuolar staining was observed with the LUM5-1 antiserum. Figure 5A shows expression of gastric (MUC6) and intestinal (MUC2) apomucin genes in the same metaplastic cell.

Samples with dysplasia, from patients with intestinal metaplasia and/or neoplasia, showed a pattern of apomucin expression similar to that observed in incomplete intestinal metaplasia: all four apomucin genes were commonly detected. Tumour biopsies obtained at gastroscopy $(n=13)$ were also analysed (table 3$)$. Regardless of the histological subtype, MUC5AC was detected in a higher proportion of tumour biopsies than in surgical specimens. This discrepancy may be due to the fact that some gastric tumours contain cells with gastric features in the superficial areas whereas invasive areas are less differentiated..$^{22}$ Results obtained with anti-MUC5AC antibodies were comparable when samples from the same patient were analysed using cryostat or paraffin embedded sections.

The pattern of Lewis/apomucin association detected in normal gastric epithelium was not 
Table 3 Apomucin expression in gastric lesions obtained at gastroscopy detected by immunohistochemistry using specific antibodies

\begin{tabular}{|c|c|c|c|c|c|c|}
\hline & \multirow[b]{2}{*}{ Gastritis } & \multicolumn{2}{|l|}{ Metaplasia } & \multirow[b]{2}{*}{ Dysplasia } & \multicolumn{2}{|c|}{ Carcinoma } \\
\hline & & Incomplete & Complete & & Intestinal & Diffuse \\
\hline MUC2 & $1 / 10$ & $10 / 10$ & $4 / 4$ & $6 / 10$ & $6 / 6$ & $3 / 7$ \\
\hline MUC4 & $6 / 8$ & $5 / 6$ & $4 / 4$ & $7 / 8$ & $6 / 6$ & $1 / 7$ \\
\hline MUC5AC & $10 / 10$ & $8 / 13$ & $1 / 3$ & $7 / 10$ & $5 / 6$ & $7 / 7$ \\
\hline MUC6 & $10 / 10$ & $9 / 13$ & $1 / 4$ & $5 / 9$ & $5 / 6$ & $3 / 7$ \\
\hline
\end{tabular}

observed in metaplastic and dysplastic lesions, and there was no correlation between expression of apomucin genes and Lewis antigens. These changes, detected in incomplete metaplasia, appear to be early events in the stomach carcinogenesis process. Examples are shown in fig $5 \mathrm{~B}$ and $5 \mathrm{C}$.

\section{Discussion}

The stomach constitutes an excellent model to study the contribution of different mucin genes to mucus function and the relationship between apomucin expression and glycosylation. In our study, we examined: (1) the association of mucin mRNA, FUT mRNA, and Lewis antigen expression in normal and neoplastic stomach samples and (2) changes in apomucin/ Lewis antigen expression in lesions representative of the stomach carcinogenesis process, including data on MUC4 apomucin.

Gastric carcinomas are histologically well defined into two main types: intestinal and diffuse. Intestinal tumours are thought to evolve from intestinal metaplasia although the precise sequence of molecular and histological events is not known, whereas diffuse tumours lack recognisable precursor lesions. ${ }^{32} 33$ Mucin gene expression is altered in both types of gastric tumours: downregulation of MUC5AC and MUC6 associated with the ectopic expression of MUC2 has been reported in stomach tumours using specific antibodies. ${ }^{21}$ Here, we have confirmed and extended previous findings on MUC2, MUC5AC, and MUC6 and have provided evidence that MUC4, an apomucin expressed in the normal intestine but not in the normal stomach, is upregulated in gastric cancers. Abnormal expression of mucin genes in gastric tumours is associated with loss of the coordinated expression of apomucins and
Lewis antigens observed in the normal stomach. Our results using normal gastric mucosal scrapings support the hypothesis that such an association results from co-regulated expression of mucin and FUT genes in a specific tissue pattern rather than from instructive signals provided by the primary sequence of the apomucin, although this idea requires formal demonstration. In stomach tumour cells, this co-regulation is lost at the level of the mucin glycosylation patterns (MUC5AC/Lewis type 1 and MUC6/Lewis type 2) and at the level of mucin and FUT transcripts. Loss of the normal glycosylation patterns detected in tumours is already present in incomplete and complete intestinal metaplastic and dysplastic cells. As previously described, mucin ${ }^{12} 13$ and glycosyltransferase ${ }^{1634}$ genes display characteristic patterns of tissue distribution suggesting that these genes may be co-regulated. Little is known of the genetic elements that control tissue specific expression of mucin and FUT genes. Regarding the latter, they may include the alternative use of multiple promoters as has been described for FUT1. ${ }^{35}{ }^{36}$ Regarding the mucin genes, a preliminary analysis of the MUC2 promoter has not disclosed until now sequences for binding of tissue specific transcription factors. ${ }^{37}$ As for MUC5AC, the amino terminal and $5^{\prime}$ flanking region of the MUC5AC gene has been cloned and the $4 \mathrm{~kb}$ fragment immediately upstream of the transcription start site contains the elements responsible for transcriptional activation of the reporter in response to Pseudomonas aeruginosa exoproducts. ${ }^{38}$ There are no published data on MUC4 and MUC6 promoters. The availability of cell lines expressing high levels of MUC5AC or MUC2, such as subpopulations of HT-29 cells, ${ }^{31} 39$ should facilitate analysis of the coordinate, or non-coordinate, expression of mucin and FUT genes.

In intestinal metaplasia, alterations in expression of gastric mucin genes and ectopic detection of MUC2 and MUC3 have been reported. ${ }^{21}$ Recently, two types of intestinal metaplasia have been described with regard to the apomucins detected: in complete metaplasia, upregulation of MUC2 is associated with a decrease in expression of MUC1, MUC5AC,
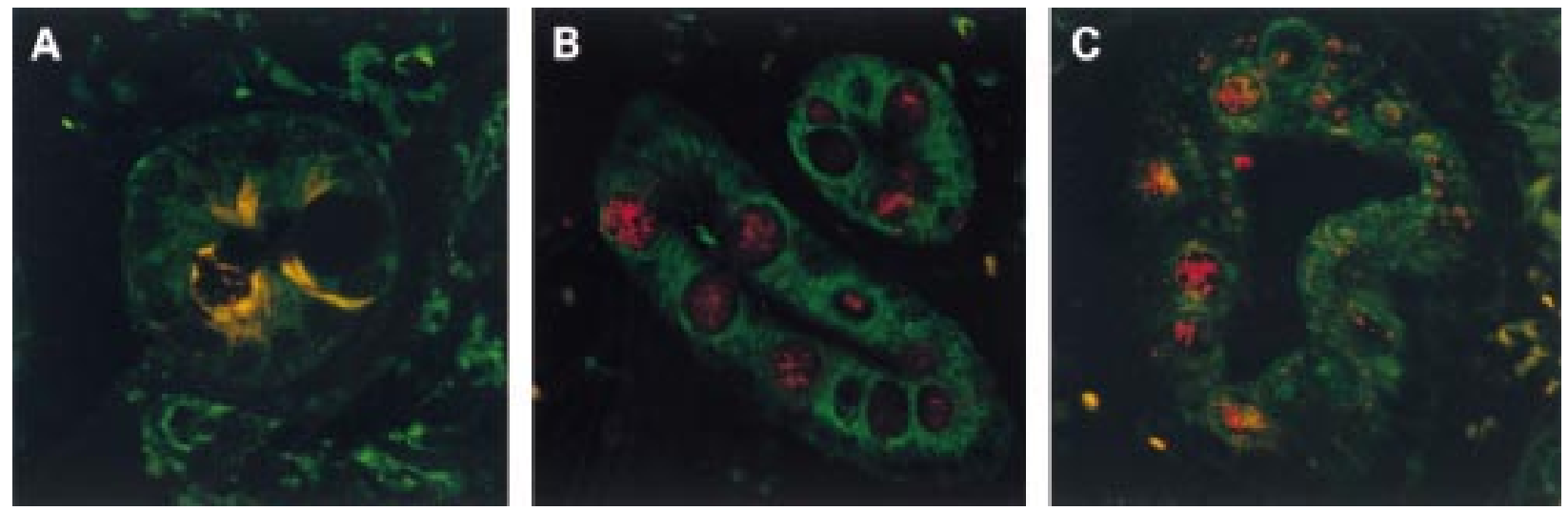

Figure 5 Expression of apomucins and Lewis antigens in intestinal metaplasia. Double labelling immunofluorescence detection of: (A) MUC2 (green) and MUC6 (red); (B) MUC4 (green) and Lewis b (red); (C) MUC5AC (green) and Lewis y (red). In incomplete intestinal metaplasia, coexpression of gastric and intestinal apomucins at the single cell level is demonstrated. In addition, the association between apomucin and Lewis antigens present in normal stomach is lost (original magnification: $A \times 630 ; B, C \times 400$ ). 
and MUC6; in incomplete metaplasia, coexpression of high levels of MUC2, MUC1, MUC5AC, and MUC6 takes place. ${ }^{40}$ Our studies, including MUC4, confirm these previous data and indicate that MUC4 is also expressed in complete and incomplete intestinal metaplastic and in dysplastic cells. Taken together, these results demonstrate that complete intestinal metaplasia is associated with coordinated activation of expression of MUC2 and MUC4, two mucin genes expressed in the normal intestine, and downregulation of MUC5AC and MUC6, the main mucin genes expressed in the stomach. Therefore, an apparently normal intestinal differentiation programme is established. In contrast, incomplete intestinal metaplasia is associated with expression of both intestinal and gastric mucin genes, indicating concomitant activation of genes associated with two distinct cell lineages in the normal gut. Because incomplete intestinal metaplasia appears to be associated with a high risk for the development of gastric cancer, these studies support the idea that this precursor lesion already harbours genetic or epigenetic alterations that may be related to establishment of an aberrant differentiation programme. Molecular studies should help to establish the genetic events that lead to intestinal gastric cancer as there is evidence that genetically unstable cell clones are detected in both types of intestinal metaplasia and in dysplasia. ${ }^{41}{ }^{42}$

Changes in apomucin and Lewis antigen expression in incomplete metaplasia are of potential relevance to the development of cancer as they involve modifications of the gastric ecological niche: carbohydrate epitopes may be important for adhesion of microorganisms to epithelial cells. For example, binding of Helicobacter pylori to the normal gastric epithelium has been shown to be mediated by Lewis $b$ antigen ${ }^{43}$ and the presence of this pathogen has been associated with specific ABO structures. ${ }^{44}$ Abnormal expression of MUC6 and Lewis $\mathrm{x}$ in the superficial epithelium of the stomach from $H$ pylori infected patients has been described ${ }^{45}$; however, in our study, MUC6 was almost exclusively detected in the deep glands, regardless of the presence of this pathogen (data not shown). More work is necessary to clarify how changes in expression of mucins and Lewis antigens can affect colonisation of the stomach epithelium by this pathogen. The presence of fucosylated structures has also been reported to be related to colonisation of the gastrointestinal epithelium by bacteria in experimental models. In mice, activation of the $\alpha-1,2-$ fucosyltransferase gene and expression of the corresponding fucosylated products in the small intestinal epithelium require the presence of the normal microflora. ${ }^{46}$ Establishment of experimental models for $H$ pylori infection, such as the FUT3 transgenic mouse, ${ }^{47}$ will be useful for studies on the role of mucin associated carbohydrate epitopes in modulating colonisation of the gastric mucosa and in the development of preneoplastic and neoplastic gastric lesions.
This work was supported by grants from Fondo de Investigación Sanitaria (FIS) 94/1228, 96/1703, and 00/0610; Comisión Interministerial de Ciencia y Tecnología (CICYT) SAF 97-0085; PRAXIS XXI (2/2.1/SAU/1356/95); Swedish Cancer Foundation; EU contract CT96-PL963222 (CA); and EU contract BMH4-CT98-3222. A L-F is a predoctoral fellow from CIRIT (Generalitat de Catalunya). The authors thank Dr J Lloreta for valuable contributions, Serveis Cientifico Tècnics, Campus de Medecina, Universitat de Barcelona for confocal microscopy analysis, and L Español for help in the preparation of the manuscript.

1 Gendler SJ, Burchell JM, Duhig T, et al. Cloning of partial cDNA encoding differentiation and tumor-associated mucin glycoproteins expressed by human mammary mucin glycoproteins expressed by human mamm

2 Lan MS, Surinder KB, Qi WN, et al. Cloning and sequencing of a human pancreatic tumor mucin cDNA. $\mathcal{J}$ Biol Chem 1990;265:15294-9.

3 Gum JR, Hicks JW, Toribara NW, et al. Molecular cloning of human intestinal mucin (MUC2) cDNA. I Biol Chem 1994;269:2440-6.

4 Gum JR, Hicks JW, Byrd JC, et al. Molecular cloning of human intestinal mucin cDNAs. $\mathcal{F}$ Biol Chem 1989;264: $6480-7$

5 Gum JR, Hicks JW, Swallow DM, et al. Molecular cloning of cDNAs derived from a novel human intestinal mucin gene. Biochem Biophys Res Commun 1990;171:407-15.

6 Porchet N, Van Cong N, Dufosse J, et al. Molecular cloning and chromosomal localization of a novel tracheo-bronchial mucin cDNA contanining tademly repeat sequences of 48 buse pairs. Biochem Biophys Res Commun 1991;175:414-22.

7 Dufosse J, Porchet N, Audie JP, et al. Degenerate 87 base pairs tandem repeats create hydrophilic/hydrophobic alternating domains in human mucin peptides mapped to 11p15. Biochem f 1993;293:329-37.

8 Crepin M, Porchet N, Aubert J P, et al. Diversity of the peptide moiety of human airway mucins. Biorheology 1991;27: 471-84.

9 Toribara NW, Roberton AM, Ho SB, et al. Human gastric mucin. Identification of a unique species by expression cloning. F Biol Chem 1993:268:5879-85

10 Bobek LA, Tsai H, Biesbrock AR, et al. Molecular cloning, sequence, and specificity expression of the gene encoding the low molecular weight human salivary mucin (MUC7). 7 Biol Chem 1993;268:20563-9.

11 Shankar V, Gilmore MS, Elkins RC, et al. P. A novel human airway mucin cDNA encodes a protein with unique airway mucin cDNA encodes a protein with unique

12 Carrato C, Balagué C, De Bolòs C, et al. Differential apomucin expression in normal and neoplastic human gastrointestinal tissues. Gastroenterology 1994;107:160-72.

13 Audie JP, Janin A, Porchet N, et al. Expression of human mucin genes in respiratory, digestive and reproductive tracts ascertained by in situ hybridization. F Histochem Cytochem 1993;41:1479-85.

14 De Bolòs C, Garrido M, Real FX. MUC6 apomucin shows a distinct normal tissue distribution that correlates with Lewis antigen expression in the human stomach. Gastroenterology 1995;109:723-34.

15 Kelly RJ, Rouquier S, Giorgi D, et al. Sequence and expres$\alpha(1,2)$ fucosyltranferase gene (FUT2). $\mathcal{F}$ Biol Chem 1995; 270:4640-9.

16 Cameron HS, Szczepaniak D, Weston BW. Expression of human chromosome $19 \mathrm{p} \alpha(1,3)$-fucosyltransferase genes human chromosome $19 \mathrm{p} \alpha(1,3)$-fucosyltransferase

17 Kelly RJ, Ernst LK, Larsen RD, et al. Molecular basis for $\mathrm{H}$ blood group deficiency in Bombay $\left(\mathrm{O}_{\mathrm{h}}\right)$ and para-Bombay individuals. Proc Natl Acad Sci USA 1994;91:5843-7.

18 Torrado J, Correa P, Ruiz B, et al. Lewis antigen alterations in gastric cancer precursors. Gastroenterology 1992;102: $424-30$

19 Murata K, Egami E, Shibata Y, et al. Expression of blood group-related antigens, $\mathrm{ABH}, \mathrm{Lewis}^{\mathrm{a}}$, Lewis ${ }^{\mathrm{b}}$, Lewis ${ }^{\mathrm{x}}$, Lewis , CA19-9, and CSLEX1 in early cancer, intestinal metaplasia, and uninvolved mucosa of the stomach. $A m \mathcal{F}$ Clin Pathol 1992;98:67-75.

20 Ura H, Denno R, Hirata K, et al. Close correlation between increased sialyl-Lewis $\mathrm{x}$ expression and metastasis in human gastric carcinoma. World f Surg 1997;21:773-6.

21 Ho SB, Shekels LL, Toribara NW, et al. Mucin gene expression in normal, preneoplastic, and neoplastic human sion in normal, preneoplastic, and neoplastic
gastric epithelium. Cancer Res 1995;55:2681-90.

22 Reis CA, David L, Nielsen PA, et al. Immunohistochemical study of MUC5AC expression in human gastric carcinomas using a novel monoclonal antibody. Int f Cancer 1997; $74: 112-21$

23 Sakamoto J, Furukawa K, Cordon-Cardo C, et al. Expression of Lewis a, Lewis $\mathrm{b}$ and $\mathrm{Y}$ blood group antigens in human colonic tumors and normal tissue and in human tumor-derived cell lines. Cancer Res 1986;46:1553-61.

24 Gambús G, De Bolòs C, Andreu D, et al. Detection of the MUC2 apomucin tandem repeat with a mouse monoclonal antibody. Gastroenterology 1993;104:93-102.

25 Hovenberg HW, Davies JR, Carlsted I. Different mucins are produced by the surface epithelium and the submucosa in human trachea: identification of MUC5AC as a major mucin from the goblet cells. Biochem $\mathcal{F}$ 1996;318:319-24.

mucin from the goblet cells. Biochem 7 1996;318:319-24.
26 Egea G, Francí C, Gambús G, et al. Cis-Golgi resident proteins and O-glycans are abnormally compartmentalized in the RER of colon cancer cells. F Cell Sci 1993;105: 819-30. 
27 Tytgat KMAJ, Büller HA, Opdam FJM, et al. Biosynthesis of human colonic mucin: Muc2 is the prominent secretory

28 Chomczynski P, Sacchi N. Single-step method of RNA isolation by acid guanidinium thiocyanate-phenol-chloroform extraction. Anal Biochem 1987;162:156-9.

29 Berrozpe G, Schaeffer J, Peinado MA, et al. Comparative analysis of mutations in the $p 53$ and K-ras genes in pancreatic cancer. Int $\mathcal{F}$ Cancer 1994;58:185-91.

30 Hanokogly I, Tanesa N, Fuchs E. Complementary DNA sequence of a human cytoplasmic actin. Interspecies divergence of 3' non coding regions. F Mol Biol 1983;163:673-8

31 Lesuffleur T, Roche F, Hill AS, et al. Characterization of a mucin cDNA clone isolated from HT-29 mucus-secreting cells: the 3' end of MUC5AC? F Biol Chem 1995;270: 13665-73

32 Laurèn P. Histogenesis of intestinal and diffuse types of gastric carcinoma. Scand f Gastroenterol 1991;180:160-4.

33 Correa P, Shiao YH. Phenotypic and genotypic events in gastric carcinogenesis. Cancer Res 1994;54:1941-3.

34 Kitagawa H, Paulson JC. Differential expression of five sialyltransferase genes in human tissues. $f$ Biol Chem lyltransferase genes

35 Koda Y, Soejima M, Kimura H. Structure and expression of H-type GDP-L-Fucose: $\beta$-D-Galactoside 2- $\alpha$-Fucosyltransferase gene (FUT1). ₹ Biol Chem 1997;272:7501-5.

36 Koda Y, Soejima M, Kimura H. Changing transcription start sites in $\mathrm{H}$-type alpha $(1,2)$ fucosyltranferase gene (FUT1) during differentiation of the human erythroid lineage. Eur F Biochem 1998;256:379-87.

37 Gum JR, Hicks JW, Kim YS. Identification and characterization of the MUC2 (human intestinal mucin) gene 5'-flanking region: promoter activity in cultured cells. Biochem f 1997;325:259-67.

38 Li D, Gallup M, Fan N, et al. Cloning the amino-terminal and 5'-flanking region of the human MUC5AC mucin gene and the transcriptional up-regulation by bacterial exoproducts. F Biol Chem 1998;273:6812-20.
39 Lesuffleur T, Porchet N, Aubert JP, et al. Differential expression of the human mucin genes MUC1 to MUC5 in relation to growth and differentiation of different mucus-secreting HT-29 cell populations. F Cell Sci 1993;106:771-83.

40 Reis CA, David L, Correa P, et al. Intestinal metaplasia of human stomach displays distinct patterns on mucin (MUC1, MUC2, MUC5AC, and MUC6) expression. Cancer Res 1999;59:1003-7.

41 Semba S, Yokozaki H, Yamamoto S, et al. Microsatellite instability in precancerous lesions and adenocarcinomas of the stomach. Cancer 1996;77:1620-7.

42 Ottini L, Palli D, Falchetti M, et al. Microsatellite instability in gastric cancer is associated with tumor location and family history in a high-risk population from Tuscany. Cancer Res 1997;57:4523-9.

43 Boren T, Falk P, Roth KA, et al. Attachment of Helicobacter pylori to human gastric epithelium mediated by blood group antigens. Science 1993;262:1892-5.

44 Mentis A, Blackwell CC, Weir DM, et al. ABO blood group, secretor status and detection of Helicobacter pylori among patients with gastric or duodenal ulcers. Epidemiol Infect 1991;106:221-9.

45 Byrd JC, Yan P, Sternberg L, et al. Aberrant expression of gland-type gastric mucin in the surface epithelium of Helicobacter pylori-infected patients. Gastroenterology 1997; 113:455-64.

46 Bry L, Falk PG, Midvedt T, et al. A model of host-microbial interactions in an open mammalian ecosystem. Science 1996;273:1380-3.

47 Falk PG, Bry L, Holgersson J, et al. Expression of a human $\alpha 1,3 / 4$-fucosyltransferase in the pit cell lineage of $\mathrm{FVB} / \mathrm{N}$ mouse stomach results in production of $\mathrm{Le}^{\mathrm{b}}$-containing glycoconjugates: A potential transgenic mouse model for studying Helicobacter pylori infection. Proc Natl Acad Sci USA 1995;92:1515-19. 